\title{
Effects of the Endothelial Nitric Oxide Synthase (Enos) T786c Genotype on the Risk of Prostate Cancer in Japanese Population
}

\author{
Satoru Sugie ${ }^{1 *}$, Norihiko Shibata ${ }^{1}$, Satoru Fukao ${ }^{2}$, Shiro Minami², Mitsumi Shibata ${ }^{2}$, Naoya $^{2}$ \\ Shibata $^{2}$, Kennosuke Takesako ${ }^{1}$ \\ ${ }^{1}$ Department of Urology, Takesako Medical Hospital, Miyazaki, Japan \\ ${ }^{2}$ Departments of Coloproctology, Ikime-Coloproctology Hospital, Miyazaki, Japan
}

Received: March 03, 2016; Accepted: March 18, 2016; Published: March 26, 2016

*Corresponding author: Satoru Sugie, Department of Urology, Takesako Medical Hospital, 2107-1 Hongo-Kitakata, Miyazaki 880-0925, Japan, Tel: +81-985-53-1212; Fax: +81-985-53-1213; E-mail: satoru_sugie@med.miyazaki-u.ac

\begin{abstract}
Objective: To evaluate the relationship between Endothelial Nitric Oxide Synthase (eNOS) T786C (rs2070744) polymorphisms and prostate cancer risk in Japanese men, and associations between eNOS polymorphisms and clinic-pathological characteristics, including Gleason grade and Prostate-Specific Antigen (PSA) grade.

Materials and Methods: We matched134 patients with prostate cancer and 86 healthy controls for age and smoking status. eNOST786C polymorphism status was determined by polymerase chain reaction and restriction fragment-length polymorphism analysis.

Results: Genotype distributions $(P=0.035)$ and allelic frequencies $(P=0.007)$ differed significantly between prostate cancer and control groups in terms of eNOST786C polymorphism (Pearson's $\chi^{2}$ test). Logistic regression analysis of case and control outcomes showed an odds ratio between CC and TT genotypes of 3.5 (95\% confidence interval $=1.2-13, P=0.015$ ), indicating increased risk of prostate cancer associated with the $C C$ genotype. Subset analysis revealed no significant associations between this polymorphism and clinic-pathological characteristics of prostate cancer.

Conclusion: The eNOST786C variant is related to increase prostate cancer risk, and may merit investigation as a potential marker for slightly elevated risk of prostate cancer. Although our results imply that rs2070744 influences susceptibility to prostate cancer, prostate cancer progression was not associated with rs2070744 in Japanese men.
\end{abstract}

Keywords: Endothelial nitric oxide synthase (eNOS); Prostate cancer; Polymorphism; Carcinogenesis

\section{Introduction}

Prostate cancer is one of the most common types of cancer and is the sixth leading cause of cancer-related deaths among Japanese men [1]. It is now a serious public health issue in Japan, with the death rate increasing over the past two decades [1]. In most cases, death from prostate cancer results from metastatic disease. Understanding the mechanisms that underlie its progression will facilitate the development of biomarkers and novel therapeutic strategies to control this devastating malignancy.

Cytogenetic and molecular studies have shown that human chromosome arm $7 \mathrm{q}$ contains a gene that may greatly affect carcinogenesis and progression of human prostate cancer [2,3]. Nitric Oxide (NO) is generated from L-arginine by 3 Nitric Oxide Synthase (NOS) iso-enzymes: neuronal Nitric Oxide Synthase (nNOS), inducible Nitric Oxide Synthase (iNOS), and endothelial Nitric Oxide Synthase (eNOS) [4,5]. The human eNOS gene is located on chromosome 7q35-36 and contains 26 exons.

Different NOS iso-enzymes are reportedly expressed by human cancers and by cancer cell lines [6,7]. eNOS strongly affects tumor growth by promoting angiogenesis [8]. Both cancerpromoting and -fighting effects have been proposed for NO, which has been shown to increase blood flow, induce angiogenesis, kill tumor cells, and reduce tumor cell adhesion $[9,10]$. NO may have a role in carcinogenesis by producing DNA strand breaks [11] and by impairing the tumor suppressor function of p53 [12]. $\mathrm{NO}$ also protects endothelial cells from tumor necrosis factor $\alpha$ (TNF $\alpha$ )-induced apoptosis [13]. In contrast, cytokine-activated endothelial NO production can kill adherent tumor cells [14]. In view of these conflicting results, the role of NO in tumor biology remains to be determined.

A functional polymorphism exists in exon 7 of human eNOSG894T (rs1799983), which tends to exhibit diminished eNOS enzyme activity in eNOSG894TT allele carriers compared with $G G$ homozygotes [15]. In addition, functional polymorphism is a point mutation of thymine to cytosine at nucleotide $T 786 \mathrm{C}$ (rs2070744) in the $5^{\prime}$-flanking region of the eNOS gene, which could significantly decrease promoter activity [16] and reduce serum NO level significantly [17]. Studies addressing the relationship between eNOS gene polymorphisms with prostate cancer and its clinical features are very scarce.

Emerging evidence for a role for eNOS in carcinogenesis prompted us to investigate the relationship between different 
alleles of this gene and prostate cancer. We therefore examined the genotypic frequency of the eNOST786C polymorphism and its association with prostate cancer susceptibility, and the relationship between eNOS polymorphisms and clinicpathological characteristics, such as Gleason grade and ProstateSpecific Antigen (PSA) grade. To the best of our knowledge, this is the first study to evaluate the contribution of eNOS polymorphisms to prostate oncology in a Japanese population.

\section{Materials and Methods}

\section{Study participants}

The study consisted of a total of 220 Japanese men, including 134 patients with histological confirmed cases of prostate cancer and 86 healthy age-, ethnicity- and smoking status-matched controls. The patients with prostate cancer were treated at the Department of Urology, Miyazaki Medical University Hospital (Miyazaki, Japan) and its related hospitals between August 2011 and October 2015. Tumor grade was evaluated using the Gleason scoring system. Controls were selected randomly from healthy individuals with no history of cancer. All participants were informed of the details, procedures and objectives of this study. During the study period, critical information, such as age and smoking status, were collected from the participants using a standardized questionnaire. This study was approved by the Ethics Committee of Miyazaki Medical University and related hospitals.

\section{Assessment of smoking status}

Information on demographics, smoking history, family history of cancer and medical history was collected during the interview. Participants were asked about their smoking status and were classified as "smokers" or "non-smokers." Those who had never smoked or had smoked only a few packs of cigarettes during their lifetime were defined as non-smokers. Those who had smoked cigarettes regularly for more than 20 years were defined as smokers. Both cases and controls were subjected to similar protocols/questionnaires by the same interviewer.

\section{eNOS genotyping}

Genomic DNA was extracted from peripheral blood leukocytes using a DNA Extractor WB kit (Wako Pure Chemical Industries Ltd., Osaka, Japan) according to the manufacturer's instructions, and eluted with $100 \mu \mathrm{l}$ TE buffer (Nacalaitesque, Tokyo, Japan). eNOST786C genotypes were determined using the Polymerase Chain Reaction (PCR)-based restriction fragment-length polymorphism assay, as described previously $[18,19]$. The following primers were used: eNOST786C, forward, 5'-TGGAGAGTGCTG GTGTACCCCA-3'; reverse, 5'-GCCTCCACCCCCACCCTGTC -3'. Reactions were performed using KAPA Taq PCR Kits (Nippon Genetics, Tokyo, Japan) in a thermal cycler (TaKaRa PCR Thermal Cycler Dice; Takara, Tokyo, Japan).

PCR conditions consisted of one cycle at $94^{\circ} \mathrm{C}$ for $4 \mathrm{~min}$, then 35 cycles of $94^{\circ} \mathrm{C}$ for $30 \mathrm{~s}, 65^{\circ} \mathrm{C}$ for $30 \mathrm{~s}$, and $72^{\circ} \mathrm{C}$ for $1 \mathrm{~min}$, with a final extension at $72^{\circ} \mathrm{C}$ for $5 \mathrm{~min}$. The PCR products were digested overnight with MspI restriction enzyme (Takara, Tokyo, Japan) at $37^{\circ} \mathrm{C}$ and the fragments separated on a $3 \%$ agarose gel. A $140-$ bp band corresponded to eNOSTT, 140-, 90- and 50-bp bands represented heterozygous individuals, and bands of 90 - and 50bp corresponded to the homozygous CC genotype (Figure 1).

\section{Statistical Analysis}

Statistical analysis was performed using the R i386 2.15.1 software package (Vienna University of Economics and Business Administration, Vienna, Austria). The significance of differences in eNOST786C genotypes between cases and controls was determined by Pearson's $\chi^{2}$ tests. Probability values $<0.05$ were regarded as statistically significant. Odds Ratios (ORs) and 95\% Confidence Intervals (CIs) for prostate cancer were calculated by multivariate logistic regression analysis after adjusting for several confounding variables such as age and smoking status.

\section{Results}

Clinico-pathological features are shown in Table 1. Mean age in years of patients and controls was $68.3 \pm 7.4$ (range: $61-75$ ) and $66.9 \pm 8.3$ (range: 59-75), respectively. Patients and controls did not significantly differ in terms of mean age distribution $(P=0.21$, Not Significant $(\mathrm{NS}))$ or relative frequencies of smokers and Non-Smokers $(P=0.24, \mathrm{NS})$.

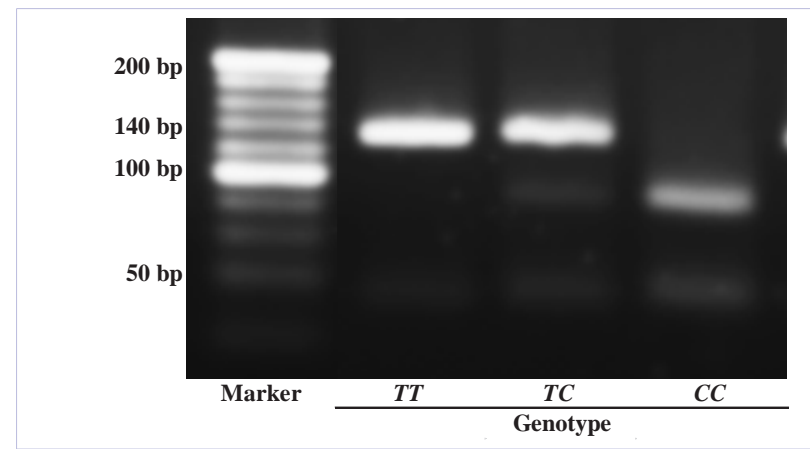

Figure 1:

Table 1:

\begin{tabular}{|l|l|l|l|}
\hline & Cases & Controls & $\boldsymbol{p}$-Value \\
\hline Age, years mean \pm SD & $68.3 \pm 7.4$ & $66.9 \pm 8.3$ & $0.21(\mathrm{NS})$ \\
\hline Smoking status & $\mathrm{n}(\%)$ & & $0.24(\mathrm{NS})$ \\
\hline Non smoker & $64(47.8)$ & $48(55.8)$ & \\
\hline smoker & $70(52.2)$ & $38(44.2)$ & \\
\hline PSA (ng/ml) mean \pm SD & $22.8 \pm 18.2$ & $2.5 \pm 0.9$ & $<0.001^{\ddagger}$ \\
\hline PSA grade & $\mathrm{n}(\%)$ & & \\
\hline Low<10 & $46(34.3)$ & & \\
\hline Intermediate $\leq 10-<20$ & $28(20.9)$ & & \\
\hline High $\geq 20$ & $60(44.8)$ & & \\
\hline Gleason grade & $\mathrm{n}(\%)$ & & \\
\hline Low $\leq 6$ & $29(21.6)$ & & \\
\hline Intermediate $=7$ & $42(31.3)$ & & \\
\hline High $\geq 8$ & $63(47.1)$ & & \\
\hline Total & 134 & 86 & \\
\hline $\begin{array}{l}\text { NS: Not significant, PSA: Prostate specific antigen } \\
\text { 'Based on Student's t-test }\end{array}$ & & \\
\hline
\end{tabular}


eNOST786C genotypic and allelic frequencies are shown in Table 2. The genotype and allele frequencies were in HardyWeinberg equilibrium. Genotypic distributions $(P=0.035)$ and allelic frequencies $(P=0.007)$ differed significantly between prostate cancer and control groups in terms of polymorphisms. The eNOST786C frequency of $C$ allele carriers was higher in patients than in controls. Logistic regression analysis of outcomes (adjusted for age at diagnosis and smoking status) showed that the $C C$ genotype was associated with increased susceptibility to prostate cancer $(\mathrm{OR}=3.5 ; 95 \% \mathrm{CI}=1.2-13 ; P=0.015)$. Subset analysis to investigate possible associations between eNOS polymorphisms and clinic-pathological characteristics such as Gleason grade and PSA grade revealed no significant associations.

\section{eNOS genotype and risk associated with Gleason grade}

eNOS genotypes were further analyzed for risk associated with less aggressive or highly aggressive disease, based on Gleason grade. Patients were then categorized into three groups based on this combined score (Gleason score $\leq 6=$ low grade; Gleason score 7 = intermediate grade; Gleason score $\geq 8=$ high grade). The results demonstrated no significant associations between genotype and Gleason grade (Table 3)

\section{eNOS genotype and risk associated with PSA grade}

Patients were categorized into three groups based on PSA value $(\mathrm{PSA}<10 \mathrm{ng} / \mathrm{ml}=$ low grade; $\mathrm{PSA} \geq 10$ and $<20 \mathrm{ng} / \mathrm{ml}=$ intermediate grade; $P S A \geq 20 \mathrm{ng} / \mathrm{ml}=$ high grade). No significant associations were found between eNOS polymorphisms and PSA grade in patients with prostate cancer (Table 3).

\section{Discussion}

Interest in genome-based cancer susceptibility has recently increased, with attention focused on SNPs in genes associated with carcinogenesis as they may contribute to individual susceptibility to cancer [20]. We consider eNOS located in chromosome 7q35-36 to be of particular interest in the search for genes that contribute to prostate cancer susceptibility.

Although associations of eNOS polymorphisms with prostate cancer indicate that its pro-and anti-tumor functions are important factors in development of this cancer, these SNPs have not yet been extensively explored. We selected the eNOST786C polymorphism from the National Center for Biotechnology Information website and found significant association of the

\begin{tabular}{|l|l|l|l|}
\hline Table 2: & \multicolumn{3}{l|}{} \\
\hline Genotype & Cases, $\mathbf{n}(\%)$ & Controls, $\mathbf{n}(\%)$ & Total \\
\hline (T786C; rs2070744) & & & \\
\hline $\boldsymbol{T T}$ & $65(48.5)$ & $54(62.8)$ & 119 \\
\hline $\boldsymbol{T C}$ & $48(35.8)$ & $27(31.4)$ & 75 \\
\hline $\boldsymbol{C C}$ & $21(15.7)$ & $5(5.8)$ & 26 \\
\hline Total & 134 & 86 & 220 \\
\hline & & & $\boldsymbol{p}=\mathbf{0 . 0 3 5}$ \\
\hline${ }^{\text {'Based on Pearson's }}{ }^{2}$ test & & \\
\hline
\end{tabular}

$C$ variant with higher susceptibility for prostate cancer in our Japanese population.

Similar results were previously reported by Safarinejad et al. [21], who showed that the $T 786 C C$ variant was significantly associated with prostate carcinoma; in Iranian populations. This $C$ allele was found to be associated with prostate cancer occurrence and increased rates of high grade and advanced disease. The eNOST786C $C$ variant in the promoter was demonstrated to be associated with lower serum concentrations of nitrite/ nitrate and reduced endothelial NO production in humans [22]. Additionally, studies have shown that the T786C C allele correlates with significant decrease in eNOS gene promoter activity compared with the $T 786 C \mathrm{C}$ allele [16].

Recently, several studies demonstrated that eNOSvariants were associated with higher risk of prostate cancer [23-27]. First, Marangoni et al. reported that, the GG and GTG894T genotypes pose a 3.3-fold higher risk of prostate cancer occurrence [23]. Medeiros et al. examined the G894TeNOS polymorphism in a series of 161 prostate cancer cases, and noted that the $G G$ genotype was associated with advanced disease and bone metastasis [24]. In another study, a statistically significant difference was found in the G894T genotype distribution between patients with advanced disease and those with localized disease [25]. On the other hand, the same authors Medeiros, et al. [26] found no association between eNOSG894T polymorphism and prostate cancer. Second, Sanli, et al. [27] investigated the relationship between the $e N O S 4 a / b$ gene polymorphism and clinical parameters of prostate cancer. They did not find any association between this polymorphism and the presence of prostate cancer. However, they reported that prostate cancer patients with the $4 a / b b b$ genotype had more localized disease and manifested bone metastasis less frequently compared with $a$ allele carriers. Medeiro, et al. [26] reported that the $a$ allele in $e N O S 4 a / b$ may facilitate survival of blood circulating tumor cells in patients with prostate cancer.

Several studies performed over last decade demonstrated that many genes are responsible in the etiology of prostate cancer. The eNOS gene, which forms NO from L-arginine, seems to be another gene involved in prostate carcinogenesis. The exact role of NO in cancer biology has yet to be determined, as it has both pro- and anti-tumor functions. In some tumors, NO reportedly augments tumor angiogenesis and provokes vasodilatation, thus accelerating tumor growth. In other tumors, a diminished amount of NOS protein was found by immunohistochemistry, implying an association between loss of NO and carcinogenesis [28]. Possibly, different tumor cells have different sensitivities to NO-mediated cytostasis or apoptosis; clonal evolution of NO-resistant and NOdependent cells may also occur [29]. Our results provide further evidence that the NO/NOS system inhibits rather than stimulates tumor growth in prostate cancer. NO derived from eNOS or eNOS itself has been shown to be cytotoxic to tumor cells by way of direct DNA damage and can be anti-tumorigenic [30].

In summary, our results are the first to indicate that prostate cancer susceptibility and risk are influenced by a common $e N O S$ genetic polymorphism, with the eNOST786C $C$ allele shown to 


\begin{tabular}{|c|c|c|c|c|c|c|c|}
\hline \multirow{4}{*}{ Genotype } & \multicolumn{3}{|c|}{ Gleason score } & \multirow{3}{*}{\begin{tabular}{|l|} 
OR $(95 \% \mathrm{CI})$ \\
Between \\
Gleason \\
\end{tabular}} & \multirow{4}{*}{$p$-Value } & \multirow{4}{*}{\begin{tabular}{|l|} 
OR $(95 \%$ CI $)$ \\
Between \\
Gleason \\
$\leq 6$ and $\geq 8$ \\
\end{tabular}} & \multirow{4}{*}{$p$-Value } \\
\hline & Low & \multirow{3}{*}{$\begin{array}{l}\text { Intermediate } \\
7\end{array}$} & \multirow{3}{*}{$\begin{array}{l}\text { High } \\
\geq 8\end{array}$} & & & & \\
\hline & \multirow[t]{2}{*}{$\leq 6$} & & & & & & \\
\hline & & & & $\leq 6$ and 7 & & & \\
\hline$T T$ & 12 & 26 & 27 & Reference & & Reference & \\
\hline$T C$ & 12 & 11 & 25 & $0.4(0.1-1.4)$ & 0.18 & $0.9(0.3-2.7)$ & 0.98 \\
\hline$C C$ & 5 & 5 & 11 & $0.5(0.1-2.5)$ & 0.29 & $1(0.2-4.4)$ & 0.98 \\
\hline \multirow[t]{4}{*}{$T C+C C$} & 17 & 16 & 36 & $0.4(0.2-1.3)$ & 0.10 & $0.9(0.4-2.5)$ & 0.98 \\
\hline & \multicolumn{3}{|c|}{ PSA (ng/ml) grade } & OR $(95 \% \mathrm{CI})$ & \multirow[b]{3}{*}{$p$-Value } & OR (95\%CI) & \multirow[b]{3}{*}{$p$-Value } \\
\hline & Low & Intermediate & High & Between & & Between & \\
\hline & $<10$ & $\leq 10-<20$ & $\geq 20$ & Low and Intermediate & & Low and High & \\
\hline$T T$ & 21 & 11 & 33 & Reference & & Reference & \\
\hline$T C$ & 17 & 12 & 19 & $1.3(0.4-4.3)$ & 0.61 & $0.7(0.3-1.8)$ & 0.51 \\
\hline$C C$ & 8 & 4 & 9 & $1(0.2-4.6)$ & 0.98 & $0.7(0.2-2.5)$ & 0.58 \\
\hline$T C+C C$ & 25 & 16 & 28 & $1.2(0.4-3.6)$ & 0.81 & $0.7(0.3-1.7)$ & 0.44 \\
\hline
\end{tabular}

OR: Odds Ratio adjusted for age; Alcohol; Smoking status; CI: Confidence Interval, PSA: Prostate Specific Antigen

increase the risk of developing prostate cancer. They are also the first results to indicate that the eNOST786C polymorphism plays an important role in prostate cancer susceptibility in the Japanese population. However, we found no significant associations between this polymorphism and clinico-pathological characteristics associated with prostate cancer progression. This apparent discrepancy could be attributed to the small sample size $(n=134)$ in this pilot study. Studies with larger sample sizes are therefore needed to clarify the relationship between the T786C polymorphism and clinico-pathological characteristics in prostate cancer. The polymorphism also merits further study as a potential genomic marker for slightly elevated risk of prostate cancer. More sophisticated gene-gene and gene-environment interactions [31], such as effects of environmental exposure to specific carcinogens, together with genotype-phenotype correlations should also be investigated in future studies.

\section{References}

1. Committee for Establishment of the Guidelines on Screening for Prostate Cancer; Japanese Urological Association. Updated Japanese Urological Association Guidelines on prostate-specific antigen-based screening for prostate cancer in 2010. Int J Urol. 2010;17(10):830-8. doi: 10.1111/j.1442-2042.2010.02613.x.

2. Karashima T, Taguchi T, Yoshikawa C, Kamada M, Kasahara K, Yuri $\mathrm{K}$, et al. Numerical chromosomal changes in metastatic prostate cancer following anti-androgen therapy: Fluorescence in situ hybridization analysis of five Japanese cases. Cancer Genet Cytogenet. 2000;120(2):148-54.

3. Nihei N, Ohta S, Kuramochi H, Kugoh H, Oshimura M, Barrett JC, et al Metastasis suppressor gene(s) for rat prostate cancer on the long arm of human chromosome 7. Genes Chromosomes Cancer. 1999;24(1):1-

4. Moncada S, Palmer RM, Higgs EA. Nitric oxide: Physiology, pathophysiology, and pharmacology. Pharmacol Rev. 1991;43(2):10942.

5. Stuehr DJ. Mammalian nitric oxide synthases. Biochim Biophys Acta.
1999;1411(2-3):217-30.

6. Klotz T, Bloch W, Volberg C, Engelmann U, Addicks K. Selective expression of inducible nitric oxide synthase in human prostate carcinoma. Cancer. 1998;82(10):1897-903.

7. Thomsen LL, Miles DW, Happerfield L, Bobrow LG, Knowles RG, Moncada S. Nitric oxide synthase activity in human breast cancer. Br J Cancer. 1995;72(1):41-4.

8. Babaei S, Teichert-Kuliszewska K, Zhang Q, Jones N, Dumont DJ, Stewart DJ. Angiogenic actions of angiopoietin-1 require endotheliumderived nitric oxide. Am J Pathol. 2003;162(6):1927-36.

9. Li LM, Kilbourn RG, Adams J, Fidler IJ. Role of nitric oxide in lysis of tumor cells by cytokine-activated endothelial cells. Cancer Res. 1991;51(10):2531-5.

10. Kong L, Dunn GD, Keefer LK, Korthuis RJ. Nitric oxide reduces tumor cell adhesion to isolated rat postcapillary venules. Clin Exp Metastasis. 1996;14(4):335-43.

11. Yoshie Y, Ohshima H. Synergistic induction of DNA strand breakage by catechol-estrogen and nitric oxide: Implications for hormonal carcinogenesis. Free Radic Biol Med. 1998;24(2):341-8.

12. Calmels S, Hainaut $P$, Ohshima H. Nitric oxide induces conformational and functional modifications of wild-type p53 tumor suppressor protein. Cancer Res. 199;57(16):3365-9.

13. Sugano M, Tsuchida K, Makino N. High-density lipoproteins protect endothelial cells from tumor necrosis factor-alpha-induced apoptosis. Biochem Biophys Res Commun. 2000;272(3):872-6.

14. Polte T, Oberle S, Schröder H. Nitric oxide protects endothelial cells from tumor necrosis factor a-mediated cytotoxicity: Possible involvement of cyclic GMP. FEBS Lett. 1997;409(1):46-8.

15. Wang XL, Mahaney MC, Sim AS, Wang J, Wang J, Blangero J, et al. Genetic contribution of the endothelial constitutive nitric oxide synthase gene to plasma nitric oxide levels. Arterioscler Thromb Vasc Biol. 1997;17(11):3147-53.

16. Nakayama M, Yasue H, Yoshimura M, Shimasaki Y, Kugiyama K, Ogawa $\mathrm{H}$, et al. T-786C mutation in the $5^{\prime}$-flanking region of the endothelial nitric oxide synthase gene is associated with coronary spasm. 


\section{Circulation. 1999;99(22):2864-70}

17. Nakayama M, Yoshimura M, Sakamoto T, Abe K, Yamamuro M, Shono $\mathrm{M}$, et al. A-786T NC polymorphism in the endothelial nitric oxide synthase gene reduces serum nitrite/nitrate levels from the heart due to an intracoronary injection of acetylcholine. Pharmacogenet Genomics. 2006;16(5):339-45

18. Bau DT, Tsai MH, Huang CY, Lee CC, Tseng HC, Lo YL, et al. Relationship between polymorphisms of nucleotide excision repair genes and oral cancer risk in Taiwan: evidence for modification of smoking habit Chin J Physiol. 2007;50(6):294-300.

19. Chang CH, Wang RF, Tsai RY, Wu HC, Wang CH, Tsai CW, et al. Significant association of XPD codon 312 single nucleotide polymorphism with bladder cancer susceptibility in Taiwan. Anticancer Res. 2009;29(10):3903-7

20.Wu GY, Hasenberg T, Magdeburg R, Bönninghoff R, Sturm JW, Keese M.et al. Association between EGF, TGF-beta1, VEGF gene polymorphism and colorectal cancer. World J Surg. 2009;33(1):124-9. Doi: 10.1007/s00268-008-9784-5.

21. Safarinejad MR, Safarinejad S, Shafiei N, Safarinejad S. Effects of the T-786C, G894T, and Intron 4 VNTR $(4 \mathrm{a} / \mathrm{b})$ polymorphisms of the endothelial nitric oxide synthase gene on the risk of prostate cancer. Urol Oncol. 2013;31(7):1132-40. doi: 10.1016/j.urolonc.2012.01.002.

22. Wang XL, Sim AS, Wang MX, Murrell GA, Trudinger B, Wang J Genotype dependent and cigarette specific effects on endothelial nitric oxide synthase gene expression and enzyme activity. FEBS Lett. 20007;471(1):45-50

23. Marangoni K, Neves AF, Cardoso AM, Santos WK, Faria PC, Goulart LR. The endothelial nitric oxide synthase Glu-298-Asp polymorphism and its mRNA expression in the peripheral blood of patients with prostate cancer and benign prostatic hyperplasia. Cancer Detect Prev. 2006;30(1):7-13
24. Medeiros RM, Morais A, Vasconcelos A, Costa S, Pinto D, Oliveira J, et al. Outcome in prostate cancer: Association with endothelial nitric oxide synthase Glu-Asp298 polymorphism at exon 7. Clin Cancer Res.2002;8:3433-7.

25. Medeiros R, Morais A, Vasconcelos A, Costa S, Pinto D, Oliveira J, et al. Endothelial nitric oxide synthase gene polymorphisms and genetic susceptibility to prostate cancer. Eur J Cancer Prev. 2002;11:343-50.

26. Medeiros R, Morais A, Vasconcelos A, Costa S, Carrilho S, Oliveira J, et al. Endothelial nitric oxide synthase gene polymorphisms and the shedding of circulating tumor cells in the blood of prostate cancer patients. Cancer Lett. 2003;189:85-90.

27. Sanli O, Kucukgergin C, Gokpinar M, Tefik T, Nane I, Seckin S. Despite the lack of association between different genotypes and the presence of prostate cancer, endothelial nitric oxide synthase a/b (eNOS4a/b) polymorphism may be associated with advanced clinical stage and bone metastasis. Urol Oncol. 2011;29(2):183-8. doi: 10.1016/j. urolonc.2009.04.011.

28. Wang YZ, Cao YQ, Wu JN, Chen M, Cha XY. Expression of nitric oxide synthase in human gastric carcinoma and its relation to p53, PCNA. World J Gatroenterol. 2005;11:46-50.

29. Jadeski LC, Chakraborty C, Lala PK. Role of nitric oxide in tumor progression with special reference to a murine breast cancer model. Can J Physiol Pharmacol 2002;8(2):125-35.

30. Sonveaux P, Jordan BF, Gallez B, Feron O. Nitric oxide delivery to cancer: Why and how? Eur J Cancer. 2009;45(8):1352-69. doi: 10.1016/j.ejca.2008.12.018.

31. Wark PA, Van der Kuil W, Ploemacher J, Van Muijen GN, Mulder CJ, Weijenberg MP, et al. Diet, lifestyle and risk of K-ras mutation-positive and-negative colorectal adenomas. Int J Cancer 2006;119(2):398-405. 